\title{
Memahami Problematik Kejahatan Transnasional: Perdagangan dan Penyelundupan Orang di Cina
}

\author{
Yusnarida Eka Nizmi \\ Hubungan Internasional, Fakultas IImu Sosial dan Politik, Universitas Riau. \\ Simpang Baru, Pekanbaru Indonesia, 28293 \\ eka_nizmi@yahoo.com \\ Submitted: 10 February 2016, Accepted: 11 March 2016
}

\begin{abstract}
This research describes about two kind of human crimes which are related each other trafficking and smuggling people in China. There are three main ideas that will be explored. First, this article analyses the causes and effects of trafficking and smuggling people that controlled by Snakeheads. Second, it focuses on the effects of trafficking in Fujian and Yunnan. Third, it explains the efforts that seriously done by China government in solving trafficking and smuggling people. It is important to examine this topic because trafficking involves horrible exploitations to women and children as the most vulnerable groups in China. Being modern society, trafficking rises as a new slavery in China.

Key words: Trafficking, Smuggling, Exploitation, Snakeheads, Inequality gender.
\end{abstract}

\begin{abstract}
Abstrak
Tulisan ini memaparkan dua persoalan kejahatan kemanusiaan yang saling berkaitan yakni perdagangan dan penyelundupan orang yang terjadi di Cina. Ada tiga hal utama yang akan dijabarkan dalam tulisan ini, pertama, menganalisa penyebab, dan dampak dari perdagangan dan penyelundupan orang yang dilakukan oleh jaringan Snakeheads. Kedua, artikel ini mengkaji perdagangan orang terhadap propinsi-propinsi di cina khususnya Fujian dan Yunan. Ketiga, artikel ini membahas upaya serius yang dilakukan oleh pemerintah Cina untuk mengatasi perdagangan dan penyelundupan orang. Dapat dikatakan bahwa Cina masih membutuhkan perjalanan panjang untuk mengatasi isu-isu ini. Penting untuk membahas topik ini karena perdagangan orang melibatkan eksploitasi yang mengerikan terhadap perempuan dan anak-anak sebagai kelompok yang sangat rentan di Cina. Masyarakat Cina kian berkembang menjadi modern, namun perdagangan orang justru menjadi "perbudakan era baru".

Kata Kunci: Perdagangan, Penyelundupan, Eksploitasi, Snakeheads, Ketidaksetaraan Jender
\end{abstract}

\section{PENDAHULUAN}

Perdagangan dan penyelundupan di Cina menarik banyak perhatian dunia karena sejumlah faktor yang menyertainya (Skeldon, 2000: 8). Pertama, masalahnya sulit sekali untuk dipecahkan. Perdagangan dan penyelundupan orang di Cina melibatkan jalur-jalur yang tidak mudah dilacak, dikelola oleh jaringan yang sangat terorganisir, dan jarak perjalanan yang panjang untuk ditempuh. Pihak-pihak terkait menelusuri dan menemukan sulit untuk menemukan pola transportasi yang mereka tempuh, yang berubah setiap waktu dan sangat terencana. Kedua, penduduk Cina banyak sekali jumlahnya yang mengalami penyiksaan. Kematian akibat masalah ini dilaporkan jumlahnya sangat banyak. Ketiga, orang-orang yang menjadi korban penyelundupan membayar mahal untuk sampai ke negara/tempat tujuan mereka, dan keuntungan dari perdagangan orang ini sangat besar. Jumlah keuntungannya menggoda banyak pihak untuk setia pada bisnis perdagangan dan penyelundupan orang ini. Banyak sekali ketakutan dan kekerasan yang menyertai kejahatan kemanusiaan yang semakin meluas ini.

Sindikat kriminal biasanya mengontrol bisnis perdagangan ini, yang memang sangat menguntungkan dan biasanya ditujukan ke negara-negara Barat yang 
kaya. Hampir sepanjang waktu, perdagangan orang menggiring terjadinya 'situasi kerja paksa dan perbudakan', yang menyeybabkan penderitaan tiada akhir bagi para korban (Skeldon, 2000: 9). Orangorang yang diselundupkan menjadi pekerja di pasar gelap, dan ini memicu terjadinya pengurangan income/pendapatan secara umum bagi penduduk di negara-negara tujuan. Pada waktu yang sama, perdagangan orang juga berkaitan erat dengan kejahatan penculikan dan eksploitasi. Semakin diperparah dengan kenyataan bahwa perdagangan orang merangsang munculnya kejahatan di tempattempat tujuan. Banyak para peneliti percaya bahwa orang-orang Cina dan geng-geng Cina adalah pengontrol utama bisnis perdagangan di seluruh dunia.

Fujian, propinsi di Selatan Cina, menjadi sebuah pusat perdagangan dan penyelundupan di Cina.

Selama lebih dari satu abad, penduduk Fujian pindah ke Barat baik secara legal maupun illegal. Orang-orang Fuji terkenal dalam sejarah emigrasi, dan ini menjadi propinsi utama yang menjadi basisnya 'human snakes' Cina, predikat untuk orang-orang yang diperdagangkan dan diselundupkan( Liu dan Pappas, 2000: 21). Ada banyak alasan fenomena ini terjadi di Fujian. Tidak seperti tempat-tempat yang lain dimana para korban berasal, mayoritasnya miskin, kasus Fujian sedikit berbeda. Berdasarkan artikel Newsweek 2000, Orangorang Fujian yang diselundupkan justru "jarang yang miskin dan putus asa", namun mereka justru mengikuti kebiasaan orang Fujian yang gampang tergoda untuk "menjadi kaya".

Ada mitos atau tradisi untuk pergi keluar negeri, untuk menghasilkan uang dan mengirimkannya ke kampung halaman, dan kemudian menjadi orang kaya diantara komunitas penduduk Fujian. Ada tekanan dari keluarga dan masyarakat untuk menghasilkan uang dari luar negeri, dan kemudian menjadi bos di kampung halaman. Seorang penduduk Fujian yang bekerja di pabrik berkata,' jika kau tidak memiliki seseorang atau keluarga yang bekerja di luar negeri, maka kau tidak memiliki 'muka' (Liu dan Pappas, 2000: 21). Itu lah sebabnya, bisa dikatakan bahwa prestige di masyarakat turut mendorong terjadinya penyelundupan illegal, yang memiliki resiko sangat besar. Banyak orang yang meninggal dalam perjalanan penyelundupan atau bahkan meninggal di penjara luar negeri; namun kematian ternyata tidak mampu menghentikan bisnis penyelundupan.

Penyelundupan telah menjadi agenda international selama beberapa tahun terakhir. Pada tahun 1993, penyelundupan manusia menjadi berita dunia dengan headline "when the Golden Venture, decrepit freighter stuffed with 286 Chinese, most from the Changle area in southern China, ran aground off Queens, New York' (Chen, 2003: 1). Dalam Dalam kecelakaan itu, 10 orang meninggal dunia dan "Golden Venture" merefleksikan kejahatan yang menyebabkan jatuhnya korban dalam jumlah yang tak terkira (Chen, 2003: 1). Pada awal 1990an, American Immigration and Naturalization Service melaporkan bahwa 90\% immigran illegal di Amerika Serikat berasal dari Fujian (Zhang, 1997: 321).

Banyaknya orang yang diselundupkan dari satu area tidak pernah terbayangkan sebelumnya. Jaringan "snakeheads" yang tinggal di Taiwan dan New York City, memiliki hubungan dengan orang-orang Fujian di Amerika Serikat. Orang-orang yang diselundupkan biasanya memiliki kehidupan yang layak di tempatnya dan mampu membayar untuk pergi ke Amerika Serikat. Mereka biasanya masih muda dan kebanyakan pria yang belum menikah.

Sepuluh tahun kemudian, pada tahun 2003, perdagangan masih terus berlangsung, dan biaya yang dikenakan adalah US\$60,000 per kepala (Chen, 2003: 1). Pada abad 21, China town di New York telah menjadi saksi dari sebuah pertumbuhan yang signifikan dari populasi penduduk Fujian. Orang-orang Fujian membuka dan bekerja di toko-toko, restauran, dan agensi tenaga kerja, mereka adalah "darah baru" di Chinatown (Kyle dan Liang, 2001: 14).

Faktor-faktor yang saling berkaitan diatas menyebabkan penyelundupan orang-orang Fujian ke Amerika Serikat tidak bisa dihentikan. Faktor-faktor ini termasuk juga motivasi ekonomi, koordinasi yang luar biasa baik dari para penyelundup, para perekrut 
lokal di Fujian, dan pertumbuhan jaringan

transportasi internasional ( Kyle dan Liang, 2001: 15).

Kolaborasi antar pihak-pihak yang terlibat dalam penyelundupan dan rencana yang matang membuat penyelundupan menjadi bisnis yang mudah untuk dilakukan.

Faktor sejarah mampu memberi penjelasan mengapa kebanyakan para penyelundup adalah orang Fujian (Zhang dan Gaylord, 1996: 5-6). Propinsi Fujian memiliki sejarah panjang penyelundupan melalui laut, dan telah menjadi rahasia umum dimasyarakat untuk melakukan perjalanan ke luar negeri. Hal yang sama bila dilihat pada abad ketujuh belas ketika terjadi konflik antara pemimpin dinasti Qing dan pendukung Ming yang menyebabkan migrasi besar-besaran ke Taiwan dan Asia Tenggara. Sejak itulah orang-orang Fujian menjadi juru kunci terjadinya migrasi. Selayaknya sejarah Cina, masa sekarang pun pelakunya masih sama. Orang-orang Fujian hidup di kota-kota besar Amerika, dan tidak selalu karena alasan kemiskinan, namun lebih kepada keinginan untuk menjadi lebih kaya, mereka bergabung dengan klan-klan ataupun keluarga mereka di Amerika Serikat.

\section{PEMBAHASAN}

TERMINOLOGI PERDAGANGAN MANUSIA

Resolusi Majelis Umum PBB 55/25 pada 15 November 2000 mengadopsi United Conventions against Transnational Organized Crime dan Protocol untuk mencegah, mensahkan sekaligus menghukum perdagangan orang, khususnya perempuan dan anak (UNODC, 2004: p. 2). Resolusi ini kemudian berlanjut ketika Sekjen PBB Kofi. A. Annan mengingatkan, perdagangan manusia khususnya terhadap perempuan dan anak yang dipaksa bekerja dan di eksploitasi merupakan "kejahatan terbesar terhadap pelanggaran hak asasi manusia" yang meresahkan PBB (UNODC, 2004: p. iv).

Menurut 'Protocol to Prevent, Suppress and Punish Trafficking in Persons, Especially Women and Children, Supplementing the United Nations Convention against Transnational Organized Crime', perdagangan orang adalah

recruitment, transportation, transfer, harbouring or receipt of persons, by means of the threat or use of force or other forms of coercion, of abduction, of fraud, of deception, of the abuse of power or of a position of vulnerability or of the giving or receiving of payments or benefits to achieve the consent of a person having control over another person, for the purpose of exploitation (UNODC, 2004: 42)

Protokol ini bertujuan untuk mencegah dan memerangi perdagangan orang, khususnya terhadap perempuan dan anak; melindungi korban dan menjamin hak asasi manusia; dan memfasilitasi kerjasama antar negara agar demi tercapainya tujuantujuan diatas. Protokol ini juga menambahkan bahwa eksploitasi memiliki makna "prositusi", bentuk lain dari eksploitasi seksual”, tenaga kerja paksa', perbudakan atau praktek-praktek yang mirip perbudakan, dan bahkan "pemindahan organ" (UNODC, 2004: 42). Lebih lanjut protokol ini juga menekankan bahwa memperdagangkan korban hingga terjadinya eksploitasi adalah sangat bertentangan dengan nilai-nilai kemanusiaan (UNODC, 2004: 43)

\section{TERMINOLOGI PENYELUNDUPAN MANUSIA}

United Nations Convention against Transnational Organized Crime' mendefenisikan penyelundupan sebagai "procurement, in order to obtain, directly or indirectly, a financial or other material benefit, of the illegal entry of a person into a State Party of which the person is not a national or a permanent resident' (UNODC, 2004: 54-55). Dalam hal ini, PBB mencari cara untuk mencegah dan memerangi terjadinya penyelundupan para migran, untuk menjaga hak-hak orang yang diselundupkan, melakukan kolaborasi antar negara-negara agar bersama-sama mengontrol perbatasan, dan memperkuat komunikasi antar lembaga/agensi yang mengawasi perbatasan (UNODC, 2004: 54, 59-60).

Sebagaimana yang disebutkan oleh PBB, perbedaan antara penyelundupan dan perdagangan orang tumpang tindih. Sulit untuk membedakan mana kasus penyelundupan atau perdagangan dan mana yang 
disertai dengan serangan/siksaan.

Beberapa orang yang diperdagangkan mengawali perjalanan mereka dengan menyetujui untuk diselundupkan secara illegal ke negara tujuan, namun sayangnya mereka harus berakhir dengan siksaan, kekerasan atau dipasa masuk dalam situasi yang penuh dengan eksploitasi.12 Sebagai contoh, mereka dipaksa bekerja dengan upah minimum yang hanya cukup untuk transportasi. Bagi para penyelundup, orangorang yang diselundupkan ini adalah korban yang potensial untuk dijual kepada pihak lain dengan biaya yang setimpal. Para penyelundup berbohong kepada orang-orang seludupan ini mengenai motif yang sebenarnya dan bagi orang-orang yang diselundupkan eksploitasi dan biaya yang mereka keluarkan adalah proses yang memang harus dialami untuk mendapatkan uang.13

Penyelundupan dapat menjadi pintu masuk terjadinya kejahatan-kejahatan yang lain, terutama bagi mereka yang percaya bahwa perdagangan jauh lebih menguntungkan. Para pelaku kriminal menyelundupkan dan menjual orang melalui jalur dan metode transportasi yang sama. Itu lah sebabnya tulisan ini mendiskusikan penyelundupan dan perdagangan orang secara bersamaan karena dua fenomena ini melibatkan jaringan kriminal yang sama, dan sama-sama berkontribusi terhadap kejahatan kemanusiaan serta memiliki dampak sosial yang identik. Perdagangan orang melibatkan orang-orang yang diidentifikasi sebagai korban, mereka yang secara fisik, pikologis, dan ekonomi dikontrol oleh para pelaku kriminal sudah terjadi sejak proses awal penyelundupan, di lokasi transit dan di negara-negara tujuan (Martinez dan Hanley, 2003).

\section{LINEARITAS KEJAHATAN TRANSNASIONAL DAN KEKERASAN}

Dalam perdagangan orang, para pelakunya memiliki pengetahuan mengenai proses perpindahan yang akan dilakukan, dan mengontrol keseluruhannya secara total. Sepanjang terjadinya perdagangan, para pelaku dapat mengambil keuntungan dari beragam cara diantaranya dengan menjual korban ke pelaku perdangan orang yang lebih tinggi levelnya, atau ke tempat-tempat yang cocok untuk praktek eksploitasi seperti pabrik-pabrik dan rumah bordil. Sesampainya di daerah atau negara tujuan, korban biasanya dijual atau dipaksa bekerja untuk memberikan keuntungan kepada penjualnya. Perdagangan orang ini erat sekali dengan kejahatan transnasional; anak yang tinggal di negara asing biasanya rentan untuk bekerja sebagai budak, dan perempuan biasanya menjadi pekerja seks. Semua keuntungan yang diperoleh didapat dari tindak kekerasan yang dilakukan terhadap korban.

Perdagangan orang adalah kejahatan yang paling mengerikan, karena menyebabkan pelanggaran hak asasi manusia dalam tingkat tertinggi. Karena yang diperdagangkan bukan barang (misal, obat-obatan), tapi justru manusia yang diperlakukan atau dijual seperti barang. Pada tahun 2004, diperkirakan ada sekitar 800,000-900,000 orang yang diperdagangkan diseluruh dunia setiap tahunnya. Para pelaku perdagangan orang menganggap bahwa perdagangan orang sebagai bisnis yang sangat meroket keuntungannya dibanding perdagangan obat dan komoditi lain.

Perdagangan orang antar negara mencerminkan bahwa banyak pemerintah yang tidak memiliki kebijakan yang efektif dan ketat terkait dengan perpindahan orang melewati batas negara (Skeldon, 2000: 8). Pemerintah kehilangan kontrol untuk mengawasi pergerakan di perbatasan. Perdagangan orang menjadi isu global, melibatkan banyak pemerintah dan organisasi internasional. Karena meluasnya fenomena ini dan besarnya kemampuan para pelaku perdagangan orang masuk menembus masyarakat, menyebabkan sulit untuk mengatasi isu ini tanpa adanya keseriusan dan kerjasama dengan berbagai pihak. Penting untuk diketahui juga bahwa kekerasan yang dilakukan juga semakin meningkat. Jika masalah ini tidak dapat segera diatasi, maka akan sangat berpengaruh terhadap peningkatan jumlah orang yang menderita akibat perbudakan era modern. Adanya globalisasi dan jaringan snakeheads semakin menambah rumit penyelesaian masalah ini dan rute penyelundupan orang semakin sulit untuk dilacak. 
KETERLIBATAN JARINGAN 'SNAKEHEADS' DALAM PERDAGANGAN DAN PENYELUNDUPAN MANUSIA DI CINA

Penyelundupan orang-orang Cina telah menjadi isu global dan secara teknik memiliki jaringan komunikasi yang tinggi. Orang-orang Cina mampu membuat passport dan visa palsu untuk tujuan kesemua negara. Pada tahun 2001, biaya untuk membuat passport bagi orang Cina menelan biaya US $\$ 5,000$, dan ini juga termasuk biaya membuat kardu resident cards. Penjual dan penyelundup yang dikenal dengan "snakeheads" adalah orang-orang yang paling mengetahui informasi terkini mengenai hukum, situasi politik, jalur-jalur penyelundupan (Kyle dan Liang, 2001: 15). Karena kedekatan geografis, sejumlah illegal immigran yang menuju Taiwan meningkat dari 1,500 pada tahun 1990an dan lebih dari 2,500 orang pada tahun 2003 (Kyle dan Liang, 2003: 2).

Taiwan, terlibat dalam penyelundupan orang-orang Fujian ke Amerika Serikat. Orang-orang Taiwan dan Fujian memiliki kemiripan dialek dan ini membuat lebih mudah bergerak. Operasi dari Taiwan dimulai pada tahun 1991 ketika orang-orang Taiwan menyelundupkan orang-orang Cina melewati Pasifik. Bisnis ini memiliki keuntungan yang sangat besar. Tanpa passpor, orang -orang Cina diselundupkan melalui jalur laut (Kyle dan Liang, 1996: 49).. Rute lain adalah ke Guanxi dan Yunnan, yang merupakan propinsi di selatan Cina, dan kemudian menuju Burma (Myanmar), kemudian ke Thailand dan negaranegara Asia Tenggara lainnya sebelum sampai di Amerika Serikat. Bangkok adalah tempat transit yang penting karena disanalah orang-orang yang diselundupkan menetap disana untuk waktu yang cukup lama. Meksiko merupakan tempat transit lainnya untuk jalur penyelundupan laut. Demikian juga dengan Amerika Utara, seperti Guatemala dan Panama; orang-orang yang diselundupkan ke Amerika Utara akan menempuh jalur transportasi ke Meksiko (Wang, 1996: 54-55)..

Orang-orang yang diselundupkan dimasukkan dalam kargo kapal, beberapa bahkan meninggal selama perjalanan. Pada Januari 2000, pihak berwenang menemukan 15 orang Fujian berada dalam kapal pengangkut raksasa, yang sampai ke Seattle, dan ditemukan 30 orang Fujian dalam kapal kargo yang tiba di Long Beach (Kyle dan Liang, 2001: 18). Dalam kasus Seattle, tiga orang yang sudah meninggal di temukan dalam kargo kontainer dari Hong Kong. Insiden yang sama juga terjadi di Kanada dan Eropa. Kasus yang paling mengerikan terjadi di bulan Juni 2002 ketika 58 orang Fujian ditemukan meninggal karena kehabisan oksigen dalam truk yang dikunci di Dover, Inggris (Kyle dan Liang, 2001: 18).

Penyelundupan dan penjualan anak juga terjadi di Cina. Pada Maret 2003, dilaporkan ada 28 anak bayi perempuan yang berusia 2-5 bulan diselundupkan di belakang bus di propinsi Guangxi (Rosenthal, 2003: 13). Bayi-bayi tersebut akan dikirim ke wilayah lain di Cina yang diperuntukkan bagi keluarga yang tidak memiliki anak yang memiliki kemampuan lebih untuk membesarkan bayi-bayi tersebut yang nantinya bisa merawat orang tuanya di masa tua nanti. Beberapa bayi dibesarkan sebagai bayi pengantin bagi para petani yang tidak mampu menikahi gadis manapun di kampungnya. Beberapa dari bayi selundupan ini kadang juga diadopsi ke luar negeri.

Bayi-bayi ini diperjualbelikan layaknya barang atau binatang akibat adanya kebijakan one-child policy yang ditetapkan oleh pemerintah Cina, dan adanya realita bahwa keluarga-keluarga di pedesaan lebih mengharapkan kehadiran anak laki-laki dibanding anak perempuan. Dengan menjual anak perempuan ke pelaku perdagangan orang, maka sebuah keluarga dapat mencoba lagi untuk memiliki anak laki-laki. Memiliki anak lak-laki seperti memiliki harta karun sementara anak perempuan dianggap sebagai beban hidup. Fenomena ini terjadi daerah-daerah Guanxi dan juga di wilayah-wilayah lain Cina (Rosenthal, 2003: 13).

Berdasarkan aturan one-child policy, kelahiran kedua akan dikenakan denda sebesar US\$3, 500, merupakan jumlah uang yang fantastis bagi keluarga petani. Yang paling banyak ditingglakan/dijual adalah bayi perempuan, namun tetap juga ada bayi laki-laki yang dtinggalkan karena alasan cacat atau karena alasan kesehatan lainnya. Bencana terjadi pada insiden Maret 2003: bayi-bayi perempuan ada di dalam selimut kapas 
dan kemudian dibungkus oleh kain-kain lainnya, dua sampai empat bayi sekaligus yang kemudian dimasukkan ke dalam tas nylon. Saat polisi datang, ketika mendapat laporan via telpon, seorang bayi perempuan telah meninggal karena kehabisan udara, yang lainnya sudah membiru karena minimnya oksigen dalam tas tersebut (Rosenthal, 2003: 1-6). Polisi menangkap 20 orang pelaku, dan bayi-bayi tersebut berasal dari satu sumber. Ketika keluarga miskin menjual bayi-bayi perempuan mereka, mereka bisa mendapatkan uang dan mendapat kesempatan untuk memiliki anak laki-laki.

Pada awal 1990an ada laporan dari tiga rute yang berbeda yang ditempuh dalam penyelundupan orangorang Cina ke Amerika Serikat. Jalur pertama diterbangkan ke Meksiko atau Kanada, dan kemudia diselundupkan secara illegal ke Amerika Serikat. Jalur kedua diterbangkan dari tempat-tempat diluar Cina dengan tujuan ke beberapa kota diAmerika Serikat, dengan menggunakan dokumen palsu. Terakhir jalur ketiga untuk menyelundupkan sejumlah orang lewat kapal pukat ikan dan kapal besar yang memuat ikan ke Amerika Serikat (Zhang dan Chin, 2003: 474). Pada akhir tahun 1990an, para penyelundup dibagi menjadi dua kategori-'big snakeheads dan little snakeheads' (Zhang dan Chin, 2003: 474). Kelompok big snakeheads menanamkan sejumlah uang dan mengawasi keseluruhan proses penyeludupan, dan mereka berada diseluruh wilayah Cina menjalankan operasi ini.

Sementara kategori little snakeheads adalah para perekrut di komunitas-komunitas lokal Cina, dan mendapatkan pendapatan melalui pembayaran dari para pelanggan dan mengumpulkan cicilan/angsuran (Zhang dan Chin, 2003: 464-475).

Secara umum, big snakeheads adalah para pebisnis yang kaya, punya koneksi, kekuatan dan punya informasi yang terbaru (Zhang dan Chin, 2003: 475). Hampir semua big snakeheads adalah warga Amerika atau pemegang kartu green card, dan beberapa dari mereka telah tinggal di Cina lebih lama dibanding di Amerika Serikat (Zhang dan Chin, 2002: 749). Perbedaan antara big snakeheads dan little snakeheads adalah: big snakeheads bisa masuk dan pergi meninggalkan Cina kapan saja dan memiliki koneksi yang sangat baik dengan pihak-pihak terkait rute-rute perdagangan orang, sementara little snakeheads tinggal di wilayah-wilayah Cina, membangun jaringan dengan berbagai pihak dan berkontribusi terhadap jaringan yang lebih luas disemua wilayah Cina (Zhang dan Chin, 2002: 750).

Jaringan penyelundupan adalah sebuah operasi yang dilakukan oleh para gugus tugas untuk mengantarkan orang ke tujuan mereka dan kemudian menerima keuntungan yang besar (Zhang dan Chin, 2002: 750). Kelompok gugus tugas termasuk para perekrut, koordinator, pengantar, pengumpul dan pembuat dokumen, pihak pemerintah, guide dan para kru-nya, dan para penagih hutang (Zhang dan Chin, 2002: 751 754). Jaringan perdagangan orang ini sudah eksis di Cina, yang mampu mengorganisir baragam kelompok orang-orang selundupan secara bersama-sama, melakukan perjalanan dalam waktu yang sama namun berbeda daerah tujuan (Chin, 2003: 57-58). Sebagai contoh, pernah ada laporan, ada sekelompok orang Cina berjumlah 60 orang yang diselundupkan melalui laut ke Korea Selatan pada Oktober 2001. Didalamnya termasuk 49 orang Fujian dari wilayah Fuzhou (Lianjiang, Changle, dan Mawei). Selebihnya adalah orang Korea yang berasal dari Heilongjiang dann propinsi Jilin di bagian timur laut Cina.

Orang-orang Fujian dibawa ke Liaoning, dengan rencana disebar ke wilayah lain. Ada kelompok lain dari orang-orang Cina yang diselundupkan dari kota Jiamusi yang dipindahkan ke propinsi Zhejiang. Dua kelompok orang selundupan ini bertemu di pelabuhan Ningbo di Propinsi Zhejiang dan kemudian diselundupkan secara bersama-sama ke Korea Selatan dengan menggunakan kapal. Perjalanan ini menelan korban 25 orang Fujian dalam perjalanan menuju Korea Selatan. Dibawah perintah kapten Korea Selatan, mayat-mayat tersebut dibuang ke laut (Chin, 2003: 57-58).

Penyelundupan orang melibatkan kelompok kejahatan terorganisir, yang bisa memindahkan "kargokargo manusia" melewati Pasifik dari satu kontinen ke kontinen lain, dengan jaringan dan koneksi para 
penyelundup di seluruh belahan dunia. Pada tahun 1990an, Amerika Serikat melaporkan bahwa "jaringan penyelundupan orang-orang Cina" memiliki koneksi di 51 negara dan mampu membuat dokumen-dokumen palsu yang diperlukan (Zhang dan Chin, 2003: 476).. Complex networks dengan efesiensi tinggi dan bertanggungjawab terhadap semua kesulitan dan kemungkinan-kemungkinan yang akan terjadi (Zhang dan Chin, 2003: 476).

Perlu dicatat bahwa jaringan penyelundupan orang membutuhkan dukungan logistik berupa uang, rencana untuk operasionalnya, yang tidak mungkin dilakukan oleh individu atau kelompok little snakeheads..(Zhang dan Chin, 2003: 476). Diperkirakan lebih dari setengah juta orang Cina diselundupkan ke Amerika Serikat dari tahun 1984 sampai ke 1993, dan antara 50,000 sampai 100,000 setiap tahunnya diselundupkan sejak tahun 1994 (Zhang dan Chin, 2002: 739).

Los Angeles adalah tempat transit utama atau tujuan bagi para pelaku penjual dan penyelundupan orang. Jika orang-orang selundupan dibawa melalui Meksiko, mereka akan sampai di Los Angeles terlebih dahulu sebelum mereka dipindahkan ke kota-kota lain seperti New York. Jika orang-orangs elundupan tersebut dibawa melalui jalur laut, Los Angeles dan pelabuhan-pelabuhan disekitarnya menjadi pelabuhanpelabuhan bagi kedatangan para immigran illegal tersebut (Zhang dan Chin, 2002: 739).

\section{KETIDAKSEIMBANGAN JENDER DAN PERDAGANGAN ORANG DI YUNNAN}

Trafficking sudah menjadi persoalan serius di wilayah-wilayah paling selatan dari Yunnan: Jiangcheng dan Menghai. Dua wilayah ini memiliki angka perdagangan orang tertinggi baik yang masuk ke Yunan maupun dari Yunnan ke Propinsi-propinsi yang lain di Cina. Dari tahun 1995 sampai dengan tahun 2000, Departemen Public Security wilayah Jiangcheng menerima 45 laporan perdagangan perempuan dan anak (ILO, 2002: p. vii). Kasus yang tidak dilaporkan tentu lebih banyak lagi. Untuk wilayah Menghai, Departemen Public Security menangani 51 kasus dari tahun 1999 sampai tahun 2000, melibatkan 85 orang yang diperdagangkan (ILO, 2002: p. 15).

Perempuan dan anak diperdagangkan untuk ratarata untuk tujuan perkawinan paksa dan adopsi. Sejumlah perempuan yang mengalami eksploitasi seksual terus meningkat. Mereka diperdagangkan ke negara-negara Asia tenggara, seperti Malaysia dan Thailand. Para pelaku perdagangan orang menipu para korban dengan beragam janji palsu seperti tawaran pekerjaan yang menarik dan gaji yang tinggi. Beberapa perempuan menjadi korban perdagangan karena minimnya pendikan dan kebanyakan dari mereka berasal dari golongan miskin dan berharap akan adanya kehidupan yang lebih baik di kota (ILO: 2002: vii-viii). Ketika para pelaku perdagangan membayar para orang tua untuk bayi-bayi yang mereka jual, mereka membuka gerbang perdagangan anak (ILO, 2002: p.viii). Perdagangan perempuan biasanya dilakukan untuk pernikahan paksa dan ekspolitasi seksual dimana bayi-bayi laki-laki juga dijual untuk adopsi.

Pada tahun 2000, pihak pemerintah Cina melawan perdagangan orang. Lebih dari 300 gang perdagangan orang direlokasi dari Yunna dan lebih dari 3.500 pelaku perdagangan orang ditahan. Dalam waktu yang sama, departemen Provincial Public Security mengirim lebih dari 100 kelompok kerja ke propinsi-propinsi lain di Cina untuk melawan kejahatan ini. Lebih dari 1800 kasus berhasil dipecahkan (ILO, 2002: p.2). Pada tahun 2000 dan 2004, pihak yang berwenang melakukan investigasi dan lebih dari 2.600 kasus berhasil dipecahkan dan lebih dari 6.000 orang polisi Yunnan yang terlibat ditangkap (Agence France Presse, 2004).

Ketidakseimbangan jender menjadi satu dari beragam penyebab terjadinya perdagangan orang diseluruh Cina. Perempuan diperdagangkan untuk tujuan perkawinan paksa. Beberapa statistik menunjukkan bahwa populasi laki-laki di pedesaaan Cina lebih besar 20-40 persen dibanding perempuan karena adanya one-child policy (Protection Project, 2002: 123-124). Keluarga-keluarga di pedesaan memilih untuk menyerahkan bayi-bayi perempuan mereka, dan praktek ini menggiring terjadinya ketidakseimbangan 
populasi jender di berbagai wilayah di Cina. Di beberapa wilayah pedesaan, kaum pria sulit sekali untuk melakukan pernikahan dan mendapatkan ahli waris. Di wilayah-wilayah miskin, rendahnya status perempuan dalam hal pendidikan dan pekerjaan membuat kasus perdagangan lebih mudah terjadi. Dalam beberapa kasus, anak-anak laki-laki menjadi komoditas untuk diperdagangkan bagi para keluarga yang membutuhkan ahli waris untuk menjalankan bisnis keluarga.

Ketidakseimbangan jender akan terus menjadi persoalan di Cina. Tidak ada cara yang mudah untuk menyelesaikan persoalan ini. Dengan tingginya persoalan ini, para pelaku kriminal akan terus melakukan penculikan, penipuan, dan penyelundupan "manusia”. Luasnya jaringan perdagangan orang yang menembus seluruh propinsi, kerjasama antara para pelaku dengan pemerintah propinsi akan terus dilakukan, meski hal ini juga tidak mudah. Pemerintah Cina harus meningkatkan hukuman, memberikan perhatian lebih pada persoalan hak asasi manusi. Jika persoalan ini tidak diselesaikan, maka situasi yang lebih buruk bisa saja terjadi.

Pada tahun 2004, kepolisian Cina melakukan aksi perlawanan terhadap perdagangan perempuan dan anak. Sejumlah perempuan yang dijual untuk tujuan pernikahan paksa dimana ketidakseimbangan jender terjadi terus meningkat secara akut (Agence France Presse, 2004). The Public Security Bureau of Yunnan melaporkan adanya sejumlah kasus penculikan dan kekerasan. Diwilayah barat daya Yunnan adalah wilayah yang paling parah. Anatara april dan Juli pada 2004, polisi menyelamatkan 85 perempuan dan anak yang diculik, namun berapa sebenarnya jumlah yang hilang tidak jelas (Agence France Presse, 2004).

Hampir secara keseluruhan, perempuan yang diculik itu dijual ke lelaki di Propinsi-propinsi seperti Henan dimana terjadi ketidaksiembangan jender dan banyak pria yang tidak bisa menemukan istri. Pada Oktober 2004, dua pria yang melakukan penculikan dan penjualan perempuan dan anak dikenakan hukuman mati dan banyak tersangka lainnya yang dikenai hukuman penjara (Agence France Presse,
2004). Mereka adalah anggota geng yang menjanjikan pekerjaan dan uang kepada para perempuan korban mereka, namun yang terjadi justru mereka menjual para korban ke luar wilayah dan luar propinsi.

Kasus perdagangan menjadi persoalan utama di perbatasan-perbatasan termasuk perbatasan antar propinsi. Beberapa perempuan dijual untuk pernikahan paksa, beberapa yang lainnya dipaksa untuk perdagangan seks dan bisa dipastikan mengalami penderitaan yang panjang akibat eksploitasi seksual. Pada masa lalu, perempuan-perempuan yang diperdagankan berusia antara 20 dan 50. Namun sekarang, kebanyakan dari perempuan tersebut berusia dibawah 20 dan remaja-remaja yang berusia diwah 12 tahun. Biasanya mereka dari daerah pedesaan Yunnan. Mereka diperdagankan ke wilayah-wilayah seperti Jaingsu, Zhejiang, Shandong, Shanxi, Guangdong dan Mongolia (ILO, 2002: 19-20). Beberapa perempuan di selundupkan ke Asia Tenggara -Thailand, Malaysia, dan Burma (Myanmar). Perempuan-perempuan ini mengalami penderitaan yang mengerikan; mereka kerapkali diperkosa, dipukul dan disiksa.

Respon Pemerintah Cina Terhadap Kejahatan Perdagangan dan Penyelundupan Manusia

Pada tahun 2000, 58 orang yang diselundupkan meninggal dalam sebuah kulkas yang dibawa truk di Dover, Inggris, dan insiden ini mengejutkan dunia (Zhang dan Chin, 2002: 739). Pada tahun 2000, pemerintah Cina menyadari adanya persoalan besar yang berhubungan dengan perdagangan manusia. Menurut Ministry of Public Security and high officials terkait urusan perempuan, operasi secara mendunia diperlukan untuk mengatasi perdagangan perempuan dan anak (China Daily, 2002). Proyeknya di inisiasi oleh All- China Women's Federation dan International Labor Organization (ILO) di Propinsi Yunnan untuk melawan perdagangan manusia. Proyek ini disebut sebagai "pilot mechanism" untuk mengatasi persoalan ini melalui kerjasama yang ekstensif antara berbagai elemen pemerintah dan komunitas. Pihak berwenang Cina menyadari bahwa seluruh masyarakat harus melawan perdagangan manusia dan poin utamanya adalah pemahaman dan perlindungan hak- 
hak perempuan dan anak.

Menurut data di lapangan, kemiskinan menjadi sebab munculnya masalah perdagangan manusia, dan pengurangan angka kemiskinan, melalui bantuan keuangan dan peningkatan kemampuan pertanian, akan membantu mengatasi perdagangan manusia. Dalam rangka mengatasi perdagangan manusia, upaya harus dilakukan oleh beberapa lembaga keamanan secara bersamaan bukan hanya satu lembaga saja (China Daily, 2002).

Yunnan merupakan satu wilayah yang paling parah terkait dengan perdagangan manusia. Ada perdagangan manusia ke daerah-daerah dimana terjadi peningkatan ketidakseimbangan jender (Agence France Presse, 2004). Antara tahun 2000 dan 2004, polisi menangkap para tersangka yang terlibat dalam sejumlah kasus penculikan. Hampir 4000 perempuan dan lebih dari 800 anak yang menjadi korban penculikan (Agance France Presse, 2004). Diseluruh dunia lebih dari 42.000 perempuan dan anak berhasil diselamatkan dari para penculik dalam kurun waktu tiga tahun sejak tahun 2001 (Agance France Presse, 2004).

Pada tahun 2000, International Program on the Elimination of Child Labor of the International Labor Organization (ILO-IPEC) mengawali pembentukan ' Mekong Sub- Regional Project to Combat Trafficking in Children and Women (IPEC-TICW) untuk mengatasi masalah eksploitasi, perdagangan seks dan tenaga kerja anak. Melibatkan Yunnan di Cina dan negara-negara lain di Indocina seperti Kamboja, Thailand, dan Vietnam. ILO-IPEC memiliki kantor di Yunnan untuk mengawasi keseluruhan agenda kerja, dan bekerja sama dengan sejumlah agensi lokal seperti lembaga pemerintah dan kelompok-kelompok perempuan. ILO-IPEC melaporkan lebih dari 1,000 perempuan dan anak diperdagangkan setiap tahunnya di Yunnan, daerah terburuk perdagangan manusia (ILO, 2002: p. vii).

Pemerintah Cina juga membuat ukuran-ukuran tertentu untuk mengatasi persoalan perdagangan manusia. Termasuk juga memindahkan para pemimpin lokal yang ketahuan terlibat dalam bisnis perdagangan orang, dan menetapkan denda bagi mereka yang terlibat (Skeldon, 2000: 29-30). Dilaporkan bahwa lebih dari 20 orang yang terlibat dan dikenai denda US \$ 3,000 karena tidak berhasil menggagalkan orangorang yang secara illegal akan dipindahkan ke wilayah lain (Skeldon, 2000: 29-30).

Pemerintah Cina meloloskan sejumlah undangundang untuk melawan perdagangan dan penyelundupan orang. Hukuman untuk para penjual dan pembeli "manusia" tergolong tinggi. Pada tahun 1973, Cina meratifikasi ILO Minimum Age Convention (No. 138). Pada tahun 1979, setuju untuk melaksanakan Convention on the Elimination of All Forms of Discrimination Against Women (CEDAW). Pada tahun 1989, Cina juga mendukung UN Convention on the Rights of the Child (CRC). Kemudian pada tahun 2002, Cina juga mendukung ILO Worst Forms of Child Labor Convention (No. 182) (ILO, 2002: p.viii).

Beberapa negara mendirikan organisasi bilateral dengan Cina untuk mengatasi perdagangan. Amerika Serikat, Kanada, dan Australia mengirimkan perwakilannya ke Cina untuk mendiskusikan issu ini. United States Immigration and Naturalization Service dan Chinese Ministry of Public Security membentuk Liaison Grup yang rutin menagadakan pertemuan di Beijing. Amerika mendirikan kantor resmi di kota-kota besar Cina seperti Shanghai dan Guangzhou, dan sering melakukan perjalanan ke propinsi Fujian untuk mengamati situasi. Pada waktu yang sama, Departement Immigration and Multicultural Affairs Australia mengirimkan agen khusus ke Beijing dan Guangzhou untuk menginvestigasi beberapa orang terkait masalah perbatasan ini (Skeldon, 2000: 29).

Ada banyak upaya untuk mengatasi persoalan ini, khususnya perdagangan orang dari pusat kota ke Taiwan, karena tingginya angka perempuan yang diperdagangkan ke Taiwan. Jumlah total orang-orang yang diperdagangkan dari Cina ke Taiwan mencapai 2, 511 pada tahun 2003, dan 84 persennya adalah perempuan. Straits Exchange Foundation (Taiwan) dan Association for Relations Across the Taiwan Straits (China) melakukan kerjasama untuk 
menyelamatkan para immigran illegal dan memulangkan mereka kembali ke asalnya (Hille, 2003: 2).

Cina telah berpartisipasi dalam konferensikonferensi internasional dalam rangka memerangi perdagangan manusia. Pada April 2003, perwakilan Cina menghadiri Second Regional Ministerial Conference on People Smuggling, Trafficking in Persons and Related Transnational Crime, yang diadakan di Bali, Indonesia. Menlu Indonesia dan Australia memimpin pertemuan, yang juga dihadiri oleh delegasi dari Korea, India, Jepang, Malaysia, Singapura, dan negara lain. Bersama dengan negara-negara tersebut, Cina memahami bahwa penyebab terjadinya kasus perdagangan dan penyelundupan orang sangat beragam dan dipengaruhi banyak aspek. Karena itu diperlukan konsensus yang kuat dan kerjasama transnasional (Second Regional Ministerial Conference on People Smuggling, Trafficking in Persons and Related Transnational Crime, 2003).. Pada Juni 2004, Cina menjadi satu dari sekian banyak negara yang hadir sebagai partisipan dalam Senior Officials Meeting di Brisbane untuk mendiskusikan dan meriview agenda kerja yang sudah diawali pada pertemuan Bali (Bali Process on People Smuggling, Trafficking in Persons and Related Transnational Crime, Senior Officials Meeting, 2004).

Dari 2001 sampai 2005, otoritas Cina menginvestigasi lebih dari 28,000 kasus perdagangan orang, menangkap lebih dari 25,000 tersangka pelaku perdagangan orang, dan menyelamatkan lebih dari 35,000 orang korban perdagangan. Pada tahun 2006, otoritas Cina menangani lebih dari 3,300, menangkap lebih dari 410 penjual orang, dan menyelamatkan lebihd ari 370 korban (www.humatrafficking.org). Ada kerjasama yang terus meningkat antara Cina, Thailand, Vietnam, dan Burma (Myanmar) yang efektif menyelamatkan para korban. Pada tahun 2007, Cina bersama-sama dengan kamboja, Laos, Burma (Myanmar), Thailand, dan Vietnam membentuk aliansi enam negara - The Coordinated Mekong Ministerial Initiative against Human Trafficking (COMMIT) -untuk mengatasi perdagangan orang. COMMIT diwakili langsung oleh pemerintah dan membangun sistem kerjasama dan kolaborasi lintas batas yang melibatkan enam negara (COMMIT Sub Regional Plan of Action, 2007).

Perdagangan orang internasional melinbatkan semua jaringan internasional yang ada dengan perencanan dan operasi yang sangat cermat (ILO, 2002: 25-26). Hanya dengan melalui kerjasama internasional pula kejahatan kemanusiaan ini dapat diatasi. Negara-negara Asia harus bekerjasama untuk beragam bidang seperti pendidikan, pertumbuhan ekonomi, dan penegakan hukum agar bisa secara berangsur mengatasi persoalan perdagangan dan penyelundupan manusia. Kerjasama internasional yang effektif akan mampu memfasilitasi penangkapan dan pemberian hukuman bagi para snakeheads dan melacak geng-geng perdagangan dan penyelundupan orang.

\section{KESIMPULAN}

Perdagangan dan penyelundupan menjadi sebuah kejahatan yang kian berkembang dan mendapat perhatian dari dunia. Fakta bahwa pemerintah Beijing dan NGOs sudah melakukan investigasi terhadap isu ini, perdagangan manusia menjadi sebuah tantangan tersendiri, karena sulitnya meredam kejahatan kemanusiaan ini. Para pelaku perdagangan dan penyelundupan orang memiliki jaringan transnasional yang luar biasa. Globalisasi adalah kata yang tepat untuk mendeskripsikan bisnis perdagangan dan penyelundupan ini. Sayangnya, perdagangan yang dilakukan adalah "manusia", dan perdagangan yang terjadi menyebabkan penderitaan yang berkepanjangan terhadap para korban dan melanggar hak asasi manusia. Peradaban masyarakat Cina memang menunjukkan kemajuan, namun perdagangan ini justru menjadi perdagangan di era modern Cina sebagai bentuk perbudakan modern, sebuah masalah yang sangat sulit untuk dicari jalan keluarnya. Pemerintah Cina menyadari betapa seriusnya eksploitasi yang terjadi pada kejahatan ini, namun fenomena ini masih memelukan waktu yang panjang untuk memeranginya. 


\section{REFERENSI}

\section{BUKU}

Hille, Kathrin. 'The Stalemate between China and Taiwan perpetuates tragedy of human trafficking', Financial Times (Japan edition), (26 September 2003), p. 2

Liang, Z., \& Ye, W. (2001). From Fujian to New York: Understanding the new Chinese immigration. D. Kyle, \& R. Koslowski (Eds), Global Human Smuggling (pp. 117-215). Baltimore, MD: John Hopkins University Press.

Martinez, Oxman, Jacqueline \& Hanley Jill, ' Human smuggling and trafficking: achieving the goals of the UN Protocols?', in Cross Border Perspectives: Human Trafficking, (20 Februari 2003) (Campell Public Affairs Institute, Maxwell School of Syracuse University).

Skeldon, R. (2000). Myths and realities of Chinese irregular migration. IOM Migration Research Series, no. 1. Geneva, Switzeland: International Organization for Migration.

Zhang, X.Sheldon. (2008). Chinese human smuggling organization: Families, Social networks, and cultural imperatives. Palo Alto, CA: Stanford University Press.

JURNAL

Chin, K, James., " Reducing irregular migration from China', International Migration 41 (3), (2003), pp. 57-58.

Kyle dan Liang, Migration Merchants, p. 17; Zheng Wang, ' Oceangoing smuggling of illegal Chinese immigrants: operation, causation and policy implications', Transnational Organized Crime (21), (Spring 1996), p. 49.

Sheldon Zhang dan Mark S Gaylord, 'Bound for the Golden Mountain: The Social Organization of Chinese Alien Smuggling', Crime, Law and Social Change (Vol. 25, No, 1, March 1996). Pp. 5-6

Wang, Zheng, ' Ocean- going smuggling of illegal Chinese immigrants: operation, causation and policy implications', Transnational Organized Crime 2 (1), (Spring 1996), p. 49.

Zhang, Sheldon dan Ko-lin Chin, 'The Declining significance of Triad Societies in transnational illegal activities: a structural deficiency perspective,' British Journal of Criminology, 43 (3), (2003), p. 474.

Zhang, $X$ Sheldon, "Task force orientation and dyadic relations in organized Chinese alien smuggling", Journal of Contemporary Criminal Justice 13 (4), (November 1997), p. 321.

Zhang, Sheldon dan Ko-lin Chin, 'Enter the dragon: inside Chinese Human smuggling organization', Criminology 40 (4), (November 2002), p. 749.

\section{WORKING PAPER}

Kyle, David., \& Zai Liang, Migration Merchants: Human Smuggling from Ecuador and China, Working Paper No. 43 (San Diego: Center for Comparative Immigration Studies, University of Carolina- San Diego, October 2001). p. 14

\section{ARTIKEL DALAM WEBSITE}

China, www.humantrafficking.org/countries/eap/china.

\section{SURAT KABAR}

Agence France Presse, ' Two sentenced to death for human trafficking in southwest China, (3 October 2004).
Agence France Presse, China to crackdown on human trafficking amid growing gender imbalance, (7 September 2004).

China Daily, 'Project to crack down on human trafficking, (4 November 2002).

Chen, W. David, 'For many Chinese, America's allure is fading, New York Times (Late Edition, East Cost), (7 September 2003).

Liu, Melinda \& Pappas Leslie, ' Bound for paradise': Fujian's emigration culture is deeply ingrained. It's migrant aren't poor, just eager to get rich,' Newsweek (International Edition), (3 Juli 2000), p. 21.

Rosenthal, Elisabeth. 'Baby girls for sale', New York Times Upfront 136 (6), (8 December 2003), p. 13.

, 'Bias for boys leads to sale of baby girls in China', New York Times (Late Edition, East Coast), (20 July 2003), pp. 1 dan 6.

\section{LAPORAN}

A Human rights report on trafficking of persons, especially women adn children: China'. The Protection Project, (March 2002), pp. 123 124.

International Programme on the Elimination of Child Labour of the International Labour Organization, Yunnan Province, China of Trafficking in Children and Women: A Rapid Assessment (Bangkok: International Labour Organization, 2002), p. Vii.

General Assembly Resolution 55/25 of 15 November 2000', in United Nations Office on Drugs and Crime, United Nations Convention against Transnational Organized Crime and the Protocols Thereto (New York: United Nations, 2004), p. 2.

Second Regional Ministerial Conference on People Smuggling, Trafficking in Persons and Related Transnational Crime, Bali, 29-30 April 2003.

Bali Process on People Smuggling, Trafficking in Persons and Related Transnational Crime, Senior Officials Meeting, Brisbane, 7-8 Juni 2004.

COMMIT Sub-Regional Plan of Action (Beijing, December 2007). 